\title{
CATEGORÍA ESTÉTICA, REFLEJO PSICOSOCIAL: SOBRE EL FRAGMENTO Y LO FRAGMENTARIO EN FRANKENSTEINDE MARY SHELLEY
}

\author{
AESTHETIC CATEGORY, PYCHOSOCIAL REFLEX: \\ CONCERNING THE FRAGMENT AND THE FRAGMENTARY \\ IN MARY SHELLEY'S FRANKENSTEIN
}

\section{ABSTRACT}

This article tries to relate, on the one hand, the novel Frankenstein by the English author Mary Shelley to the sociocultural context — mainly artistic and philosophical — in which it was conceived, paying particular attention to the emergence of an aesthetic-epistemological category that, as we will explain, marked the understanding of the authors and creators regarding their surrounding reality: the fragment. On the other hand, we try to approach the figure of the author as a tool for perceiving how the fragment — understood in this case as a psychosocial reflex - is a key piece to build a complete portrait of the main characters of Frankenstein.

Key words: Frankenstein, fragment, aesthetics, psychosocial, cultural history. 


\section{RESUMEN}

Este artículo trata de relacionar, por un lado, la novela Frankenstein de la autora inglesa Mary Shelley con el contexto sociocultural — principalmente artístico y filosófico- en el que fue concebida, atendiendo particularmente al surgimiento de una categoría estéticoepistemológica que, según expondremos, marcó el entendimiento de los autores y creadores respecto a la realidad circundante: el fragmento. Por otro lado, tratamos de acercarnos a la figura de la autora como una herramienta de comprensión acerca de qué manera el fragmento -entendido en este caso como reflejo de índole más bien psicosocial- es pieza clave para construir un retrato completo de los personajes principales de Frankenstein.

Palabras clave: Frankenstein, fragmento, estética, psicosocial, historia cultural.

Fecha de recepción: 2 de septiembre de 2019.

Fecha de aceptación: 9 de octubre de 2019.

Cómo citar: Bittencourt Sarmiento, Amanda, «Categoría estética, reflejo psicosocial: sobre el fragmento y lo fragmentario en Frankenstein de Mary Shelley», en Actio Nova: Revista de Teoría de la Literatura y Literatura Comparada, 3 (2019): 340-366.

DOI: https://doi.org/10.15366/actionova2019.3.014 


\section{INTRODUCCIÓN}

En el pasado año de 2018 se cumplieron 200 años de la publicación de la primera edición de Frankenstein o el Moderno Prometeo ${ }^{1}$, la más aclamada novela de Mary Wollstonecraft Shelley (de soltera Godwin) (1797-1851), hija de uno de los más controvertidos y revolucionarios matrimonios de la Gran Bretaña de aquel momento, los filósofos y críticos políticos Mary Wollstonecraft (1759-1797) y William Godwin (1756-1836). Sin embargo, Mary Shelley es conocida, por fortuna, más allá de su ascendencia y de su matrimonio con el poeta y filósofo político Percy Bysshe Shelley (1792-1822), gracias a que Frankenstein se ha convertido en una de las obras canónicas de la literatura occidental. Lo cierto es que hace falta adentrarse verdaderamente en el mundo que nos presenta Mary Shelley en Frankenstein para percibir que la autora escribió más que una historia de terror con tintes góticos, cuya recepción en las centurias posteriores estuvo marcada mucho más por las numerosas adaptaciones cinematográficas que se hicieron de su historia — que potencian, en la mayoría de los casos, los elementos propios del género de terror, en detrimento de otros aspectos que permean la historia original — que por toda la complejidad que alberga el texto literario.

La obra nació en 1818, en una Inglaterra marcada por la incipiente Revolución Industrial, los fervorosos debates científicos y un panorama político profundamente influido por unos ideales revolucionarios que habían hecho temblar los cimientos de Europa pero que se habían mostrado, en su mayoría, endebles. Mary Shelley, que por aquel entonces contabilizaba no más que dieciocho años de vida, inspirada por el reto lanzado por Lord Byron (1788-1824) en una gélida Villa Diodati a las afueras de Ginebra, dio vida a Frankenstein, trayendo a la luz a un mito que marcaría el panorama cultural, haciéndose inmortal en sus múltiples facetas e interpretaciones en los más diversos medios artísticos.

Lo cierto es que la idea principal de la novela resulta, como poco, inquietante, sobre todo si se tiene en cuenta la edad de Shelley cuando la escribió. El argumento central de la misma gira en torno a la figura de un atormentado científico, Víctor Frankenstein, quien influido por sus estudios de filosofía y ciencia natural, decide intentar crear vida a partir de la muerte, trayendo al mundo a un ser construido a través de los fragmentos de individuos muertos, despertado gracias al uso de la electricidad; dicho concepto, así como las

${ }^{1}$ En 1831, Mary Shelley publica una nueva versión de la novela, añadiendo una introducción en la que explica el proceso de creación de la misma y corrigiendo cuestiones de estilo del texto respecto a la primera edición de 1818. En este trabajo manejaremos la traducción al castellano de José C. Vales de la edición de 1831: Shelley, Mary (2014): Frankenstein o el Moderno Prometeo, Barcelona, Espasa Libros. 
posibilidades y el poder intrínsecos al mismo, empezaban, a su vez, a formar parte de los principales debates científicos decimonónicos. Una vez se da cuenta de su error al crear el «monstruo», Víctor lo abandona a su propia suerte, desencadenando los trágicos - y típicamente románticos — sucesos que tienen lugar en el devenir de la historia.

Ríos de tinta han corrido sobre Frankenstein, cuya riqueza filosófica, cultural y estética, la convierten en típica hija de su tiempo, marcando, asimismo, su carácter como producto de la cultura popular. Teniendo esto en cuenta, trataremos de presentar aquí una lectura de Frankenstein partiendo de la base de que nuestro caso de estudio, así como el monstruo sin nombre ${ }^{2}$ sobre el que versa, únicamente puede ser comprendido en toda su complejidad si vamos más allá de la estereotípica imagen que tenemos de él. Para lograrlo, debemos aumentar la resolución del enfoque y analizamos los principales fragmentos que lo componen y a los que hace referencia. Ahora bien ¿de qué clase de fragmentos estamos hablando?

Durante el siglo XIX, los convulsos acontecimientos político-sociales que asolaron Europa tuvieron su eco en el terreno filosófico y artístico, dando lugar al surgimiento de una categoría estético-epistemológica que trataba de dar respuesta a los retos que suponía la constitución de una sociedad «moderna»: el fragmento. Numerosos intelectuales, como Friedrich Schlegel (1772-1829) o Friedrich Schiller (1759-1805) en el terreno alemán, teorizaron sobre la importancia del fragmento como categoría; dicha importancia radicaba en una nueva forma de aprehender y conocer la realidad, que se entendía fragmentaria y limitada, frente a un sistema que había marcado el pensamiento filosófico anterior, creyéndose aglutinador, pero mostrándose epistemológicamente inalcanzable en la nueva realidad. De igual manera, los artistas empiezan a responder a una nueva forma de mirar del espectador, antes arraigada en la «organicidad» clasicista, pero ahora capaz de reconocer el potencial estético del fragmento, más allá de un memento mori; así, primero se acercan a contemplar estos «fragmentos encontrados», aprehendiendo su belleza escindida, para después evocarlos una y otra vez en sus obras artísticas, ahora de forma intencionada (Fig. $1)^{3}$.

\footnotetext{
${ }^{2}$ La criatura acabó bautizada con el apellido de su creador en la primera adaptación teatral de la obra titulada Frankenstein: An Adventure in the Macabre escrita por la dramaturga Peggy Webling, que tuvo su estreno en febrero de 1930 en Londres (Neibaur, 2017: 11). Esta licencia dramática dejó una imborrable huella en la historia cultural del «mito» Frankenstein.

${ }^{3}$ Ejemplos de obras artísticas que plasman la fascinación por lo fragmentario y la ruina son los cuadros del pintor alemán Caspar David Friedrich, figura clave del movimiento romántico.
} 


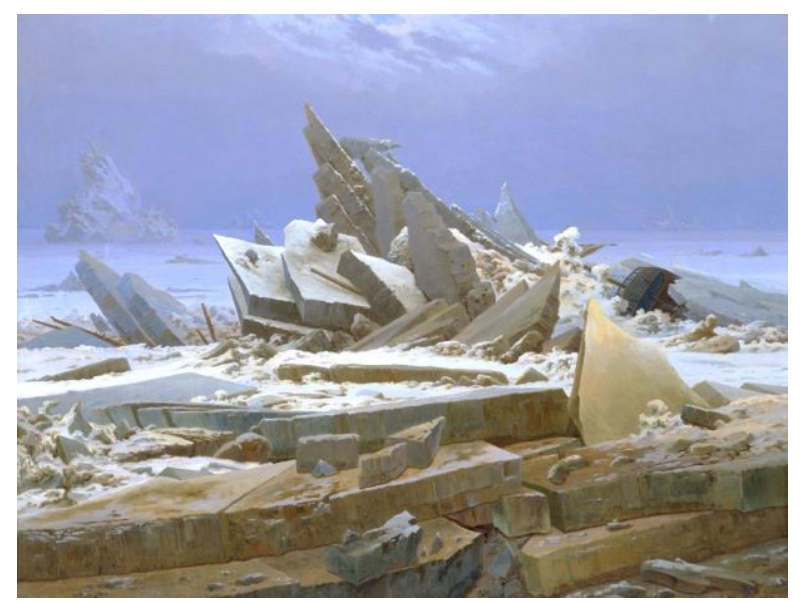

Fig. 1: Mar de Hielo (Die gescheiterte Hoffnung), Caspar David Friedrich, 1823-24.

Kunsthalle, Hamburg (C Hamburger Kunsthalle / Foto: Elke Walford)

Referencia: https://www.hamburger-kunsthalle.de/sammlung-online/caspar-davidfriedrich/das-eismeer (última consulta en 31/08/2019)

Quizá lo más emblemático de la criatura ensamblada por Víctor Frankenstein sea su naturaleza fragmentaria, tanto externamente, en una apariencia física derivada de un «ensamblaje» de cuerpos muertos, como internamente, en una psique corrompida, como resultado del rechazo de su propio creador y, por extensión, de su inadecuación en la sociedad. Cabe recordar, sin embargo, que el «monstruo» era bueno en esencia.

Cuando hablamos del fragmento en la obra - y en sus ecos posteriores- nos estamos refiriendo a múltiples lecturas que encuentran en el fragmento su telón de fondo; en dos de dichas lecturas nos apoyaremos para desarrollar este trabajo, son ellas: un contexto decimonónico que veía las consecuencias, pero a la vez posibilidades estéticoepistemológicas de lo fragmentario, y las claves autobiográficas de una mujer-autora psicológicamente escindida. Ambas son, consideramos, de capital importancia para comprender las complejidades que permean la novela, especialmente las que conciernen a la construcción de los dos personajes principales de la misma. 
1. EL FRAGMENTO COMO CATEGORÍA ESTÉTICO-EPISTEMOLÓGICA EN EL SIGLO XIX

Decir que el «Romanticismo» fue uno de los movimientos que más fuertemente marcó el devenir del arte no es exagerar; decir también, que, desde su heterogeneidad y fragmentariedad, consistió en un movimiento «franksteniano» por excelencia, no parece una analogía descabellada. En el siglo XIX tuvo lugar un importante cambio en el modo de ver — tanto respecto a las obras de arte como, y principalmente, a la figura del autor- que afectó considerablemente a la configuración de las teorías del arte que aún hoy siguen en boga. Como es bien sabido, en Alemania el Romanticismo alcanzó un alto grado de expresión, dando lugar a las más prolíficas manifestaciones artísticas, en todas las vertientes creativas. Desde una nación aún fragmentada, los intelectuales alemanes asistieron al fracaso de la Revolución en Francia, viendo en dicho infortunio la ruina de los ideales liberales de igualdad y comunión de los hombres. Por otro lado, los incipientes cambios industriales configuraban una realidad que alejaba al individuo cada vez más de la naturaleza. Frente a estos problemas de carácter político-social que provocaban la escisión del sujeto, se erige una categoría estético-epistemológica cuyos ecos reverberaron en la Europa del XIX: el fragmento. Como mantiene Simón Marchán Fiz: «Como entrevieron con lucidez los nuevos «modernos», sobre todo Schiller y F. Schlegel, la fragmentación es la categoría por antonomasia de la modernidad que se confronta tanto a la organicidad de la obra clasicista como a la homogeneidad de sus codificaciones.» (Marchán Fiz, 2010: 142)

Desde los más tempranos atisbos del Romanticismo en Alemania, la consciencia de la escisión del sujeto se hace presente en el pensamiento de Friedrich Schiller, uno de los principales representantes del Frübromantik. Es interesante evocar aquí a Schiller puesto que, en sus escritos, principalmente, el fragmento aparece como una categoría estéticoepistemológica profundamente marcada por lo político y lo social; asimismo, el autor pone de manifiesto una realidad que está directamente relacionada con esa escisión del sujeto moderno, es decir, su progresivo alejamiento de la naturaleza y los peligros que ello conllevaba. Su principal obra a este respecto es Sobre la educación estética del hombre, un compendio de cartas enviadas al príncipe Felipe de Augustenburg, publicadas en 1795, con marcado cariz político al reaccionar ante el fracaso de los ideales revolucionarios. Decir que la visión que tenía Schiller de su presente era pesimista parece acertado si tenemos en cuenta todas las críticas políticas y sociales que despliega en sus obras. Las Cartas ponen de 
manifiesto, como hemos dicho, los sentimientos que Schiller albergaba acerca del fracaso de la Revolución y los ideales que la caracterizaban; el teórico se muestra desesperanzado frente a los rumbos de la sociedad. Como ilustrado y liberal, él se oponía fuertemente al modelo absolutista del Estado, pero, al mismo tiempo, repudiaba el radicalismo llevado a cabo sobre todo en el «Reino del terror».

Ahora bien, la tensión entre razón y naturaleza son un continuum en la obra de Schiller, como hemos mencionado, y es éste el gran problema que el hombre moderno, en tanto que individuo social, debe tratar de solucionar. Es uno de sus principales males. Este conflicto debería solucionarse mediante una unión armónica entre sentido y racionalidad, en tanto que facultades igualmente necesarias para la experiencia humana. Relacionado con este alejamiento de la naturaleza, Schiller pone de manifiesto otra preocupación: la fragmentación el individuo; respecto a esta realidad, que encarna también, por otra parte, una crítica hacia la incipiente industrialización y a la mecanización del trabajo, Schiller dice:

El placer se desvinculó del trabajo, el medio de su finalidad, el esfuerzo de la recompensa. Ligado eternamente a un único y minúsculo fragmento del todo, el hombre mismo evoluciona sólo como fragmento; no oyendo más que el sonido monótono de la rueda que hace funcionar, nunca desarrolla la armonía que lleva dentro de sí, y en lugar de imprimir a su naturaleza el carácter propio de su humanidad, el hombre se convierte en reflejo de su oficio, de su ciencia. (Schiller, 1990: 149)

Consciente de todos aquellos males que acechaban al hombre moderno, Schiller propone una nueva forma de relacionarse con el mundo, tarea de todos los individuos, algo que es posible concluir de la lectura de sus Cartas: la educación del ser humano a través de la estética y del desarrollo de la sensibilidad (Marchán Fiz, 2010: 255-259), entendiéndose lo estético como motor de cambio que motivaba una nueva actitud en las relaciones de los sujetos entre sí y con el mundo circundante; a través de la estética, el hombre moderno podría alcanzar la libertad, podría huir de las ataduras de su presente. Él así lo atestigua en la Carta Octava: «La necesidad más apremiante de la época es, pues, la educación de la sensibilidad»y «que la cultura estética...es el medio más eficaz para mejorar los defectos o formas de decadencia propias de la época: el embrutecimiento y la relajación» (Schiller, 1990: 171). El embrutecimiento se entiende, por un lado, como "el alejamiento de la naturaleza por parte de las clases «populares» y, por otro lado, como la relajación y negación de la naturaleza por parte de las clases más «cultivadas»" (Marrades, 1997: 96). 
Ahora bien, ¿cuáles son las herramientas, según Schiller, que el hombre moderno debe tener para lograr alcanzar este estado armónico entre razón y sentido, razón y naturaleza? Como hemos mencionado, debe centrarse en su educación estética para lograr liberarse de las ataduras de las consecuencias que esta dicotomía tenía sobre su experiencia respecto al mundo circundante. Cabe mencionar que la estética para Schiller - y para el pensamiento Romántico, en general — no se reducía a lo visual ni a las obras de arte (entiéndase visuales, literarias, musicales...) propiamente dichas, sino que ésta abarcaba algo mucho más grande, englobaba toda la vida y la realidad. La estética, en tanto que reguladora de la vida de los individuos, dispone sus herramientas para que éstos puedan alcanzar su libertad. Es curioso darse cuenta de que, si bien Schiller, por un lado, denunciaba la fragmentación del sujeto como una situación eminentemente problemática, por el otro reconocía los valores estéticos de lo fragmentario, reflejado en las ruinas, en los paisajes nostálgicos típicos del gusto romántico. Esto pone de manifiesto, pues, cómo la categoría del fragmento se encontraba envuelta en paradoja, consistiendo en algo susceptible de temor y denuncia, pero también de admiración estética.

Otro gran teórico alemán del fragmento, entendido en diferentes términos, influido esencialmente por Gotthold Ephraim Lessing (1729-1781) y Nicolas Chamfort (1741-1794) fue un importante representante del Frühromantik, perteneciente al círculo de Jena: Friedrich Schlegel (1772-1829). Sus ideas sobre el fragmento se exponen sobre todo en el Athenauem, revista que fundó en 1798 con su hermano August Schlegel (1767-1845). Para Schlegel, el fragmento se opone esencialmente al sistema, se opone a la totalidad; en el supuesto carácter completo y cerrado del sistema reside un problema, puesto que existe imposibilidad en la aprehensión de un «todo», ya que lo absoluto no se puede conocer. Al ser la naturaleza misma del pensamiento del «yo» algo limitado, un intento de sistematizar a la realidad o la experiencia estética acabaría por ser falaz, puesto que es el fragmento el que encarna un constante devenir ${ }^{4}$. Al referirse a las obras de los «modernos», Schlegel mantiene: «Muchas son las obras de los antiguos que se han convertido en fragmentos. Muchas son las obras de los modernos que ya eran fragmentos desde el comienzo» (Schlegel, 2009: 64); aquí el autor

${ }^{4}$ Cabe tener en cuenta, sin embargo, que el pensamiento de Schlegel respecto a la dicotomía fragmentaciónsistema sufriría transformaciones en el devenir de su obra, como mantiene Walter Benjamin: «[...]Schlegel, por el contrario, ni por lo más mínimo se reconoció jamás como enemigo de los sistemáticos. Además, pese a todo su aparente cinismo, significativamente en su madurez, y según sus propias palabras, nunca fue un escéptico [...] Los fragmentos publicados por Windischmann ofrecen testimonio en abundancia de que desde el año 1796 estuvo reflexionando rigurosamente sobre la esencia del sistema y la posibilidad de su fundamentación» (Benjamin, 2017: 51) 
reconoce esa transición del fragmento como algo inevitable, inherente al paso del tiempo que afectaba directamente a las obras antiguas, a algo conscientemente evocado por los artistas, cuyas obras nacen siendo fragmentos. Asimismo, en el «Fragmento 206» de su Athenaeum, Schlegel mantiene que: «Como una pequeña obra de arte, un fragmento debe estar aislado del mundo que lo rodea y ser, en sí mismo, acabado y perfecto como un erizo.» (Schlegel, 2009: 105)

Ahora bien ¿cómo se traduce en las obras artísticas este nuevo modo de concebir, entender y admirar el fragmento? En su libro The body in pieces: the fragment as a metaphor of modernity (1995), Linda Nochlin presenta un interesante análisis de cómo el fragmento surge como un modo de representación icónico, especialmente relacionado con la destrucción y la Revolución en la Francia de finales del siglo XVIII y comienzos del XIX; dicha forma de representación, que encuentra su génesis en algo tan violento como una cultura del terror que utilizaba la decapitación como forma de enjuiciamiento, en un principio está relacionada con la ruptura con el pasado y todo aquello que éste representaba —algo que tiene plena coherencia con el momento histórico-político en cuestión,- - pero paulatinamente empieza a convertirse en un reclamo estético (Nochlin, 1995: 8). Así, para ejemplificar esta visión estética del fragmento, Nochlin evoca la figura de un importante pintor francés del siglo XIX, Théodore Géricault (1791-1824). En su serie de cuadros que representan cabezas decapitadas (Fig. 2), más allá del contenido grotesco, Géricault, por cómo presenta la composición, trata de ensalzar las características estéticas de estas imágenes (Nochlin, 1995: 21). Asimismo, plantea Nochlin, el surgimiento del impresionismo como técnica que encarna la estética de la fugacidad está relacionado con esa nueva forma de ver del sujeto moderno, quien se ve en un entorno cambiante y retazado, a saber, fragmentado, y trata de captar su esencia, a través de nuevos motivos y técnicas. Asimismo, el eclecticismo arquitectónico pone de manifiesto esa nueva visión que encarna, por un lado, un reclamo al pasado y, por el otro, una necesidad de renovación. 


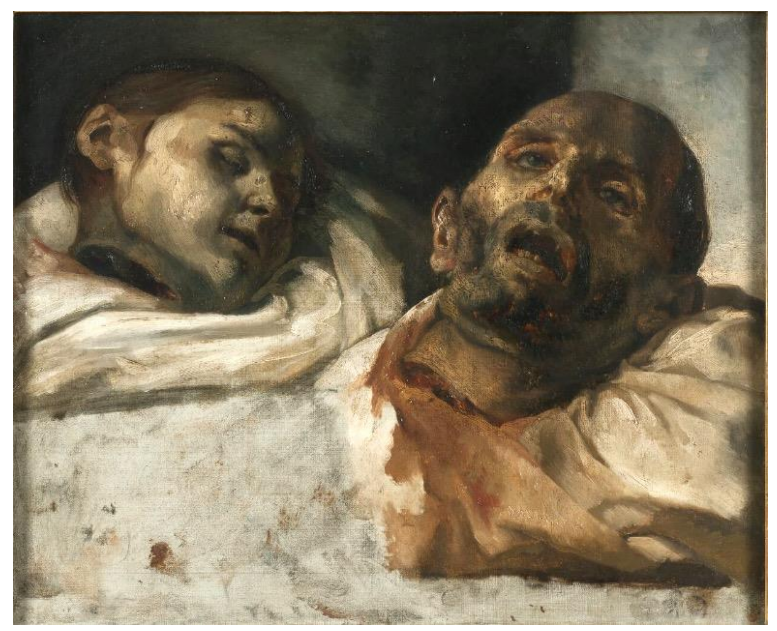

Fig. 2: Estudio de dos cabezas cortadas (Têtes coupées), Théodore Géricault, 1819.

Nationalmuseum, Sweden. (Foto: Erik Cornelius)

Referencia:http://collection.nationalmuseum.se/eMP/eMuseumPlus;jsessionid=75 058FFFC4228698790920A36144D394.node1?service $=$ direct $/ 1 /$ ResultListView $/$ res ult.t1.collection_list. $\$$ TspTitleImageLink.link\&sp $=10 \& s p=S$ collection\&sp $=S$ fieldVa lue \&sp $=0 \& \mathrm{sp}=0 \& \mathrm{sp}=3 \& \mathrm{sp}=\mathrm{SdetailList} \& \mathrm{sp}=0 \& \mathrm{sp}=\mathrm{Sdetail} \& \mathrm{sp}=0 \& \mathrm{sp}=\mathrm{F} \& \mathrm{sp}=\mathrm{T} \&$ $\mathrm{sp}=1$ (última consulta en 31/08/2019).

No es de extrañar, por otro lado, que la concepción del fragmento como una categoría estética tenga lugar especialmente en el siglo XIX, momento en el que se valora el recurso a lo onírico, lo desconocido y lo inesperado. Así, lo fragmentario entronca directamente con los imaginarios, es una llamada a la participación del espectador en la posible unión de dichos fragmentos; o, quizá, responda únicamente a la aceptación de lo fragmentario como bello en sí mismo, completo en su propia limitación. Ahora bien, por otro lado, esta forma de ver el fragmento, que es a la vez reclamo estético y evocación del pasado, se relaciona claramente con la valorización de la ruina. La presencia de la ruina en las obras de muchos pintores románticos va en contra de los preceptos de lo «clásico» (Marchán Fiz, 2008: 427-446), encarna lo anti-clásico por naturaleza, por lo que no resulta extraño pensar que se convirtiera en uno de los temas favoritos de artistas como Caspar David Friedrich (1774-1840), pintor alemán que se mostró profundamente reaccionario frente a muchos de los valores clasicistas. La ruina, a priori, representa desequilibrio, desorden, imperfección; fragmentación. Asimismo, en los cuadros de Friedrich encontramos la plasmación de una categoría estética que, así como para Schiller, podría constituirse como un motor de cambio que conectara al hombre nuevamente con sus sentidos y permitiera que éste, a través de la experiencia estética, se hermanara nuevamente con la naturaleza y lograra ser consciente de su escisión y fragmentación, tratando, así, de paliarla: lo sublime. 
Ahora bien, ¿de qué manera Frankenstein entronca con esa nueva visión estéticoepistemológica del siglo XIX relacionada con el fragmento? El primero —y prácticamente el único_- que nos habla brevemente de ello es Chris Baldick:

By stressing clearly the beauty of the component parts and the ugliness of the finished combination, Mary Shelley is isolating and dramatizing a problem which was in her time central to philosophical, and by extension to aesthetic and political discussion; namely the question of the relation of parts to wholes $[. .$. Friedrich Schiller's response to the French Revolution and the social fragmentation it threatened is to offer the harmonizing properties of art as a cure for the disintegrating tendencies of the age $[. .$.$] Now that individual has become$ just a stunted fragment, society can be little more than a monstrous aggregation of incomplete parts. From such diagnoses of the disorganization of European society, a whole tradition of culture-criticism was to develop in the nineteenth century. The fragmented society, the patchwork or clockwork individual - these become the themes of Romantic social analysis from Schiller to Carlyle and beyond. Mary Shelley's Frankenstein takes it place within this pattern of Romantic contrasts between lifeless parts and living wholes, partly as a dramatization of that principle of inorganic aggregation which Schiller saw as the modern disease. (Baldick, 1990: 33-35)

Creemos que el análisis propuesto por Baldick es del todo acertado, especialmente cuando menciona la relación entre lo propuesto por Schiller acerca del individuo como fragmento y la sociedad como un conjunto de dichos fragmentos, siendo la figura del «monstruo» de Mary Shelley una metáfora de dicha realidad.

No parece casual que la criatura ideada por la autora se caracterice por una naturaleza físicamente fragmentada, sobre todo si se tiene en cuenta que la misma ha nacido así (como las obras «modernas», como mantenía Schlegel) pero que su psique haya sido retazada a posteriori (de igual manera que el hombre «moderno» de Schiller, una vez se ha alejado de la naturaleza y del conjunto de sus facultades), fruto de un abandono total por parte de su creador, una fuerte inadecuación social y una búsqueda infructuosa por su identidad. De igual manera, Víctor Frankenstein encarna la realidad del alejamiento del hombre respecto a la naturaleza, como denuncia Schiller, que acaba por fragmentarlo; al entregarse indiscriminadamente a los avances propios de su momento, que le hacen perderse entre los rincones de una «mala praxis» de la técnica y la ciencia, acaba encontrándose con su ruina. Podríamos decir, pues, que, si bien la criatura nace estéticamente fragmentada, su psique y su «espíritu» se fragmentan a través de su contacto con el mundo exterior ${ }^{5}$. El Dr. Frankenstein, sin embargo, si bien representa una «unidad» estética, posee una moral y una

${ }^{5}$ Esto está relacionado, entre otras cosas, con el «buen salvaje» de Rousseau. 
personalidad débiles, filtrándose los comportamientos transgresores en su experiencia vital sin mayores dificultades.

Dicho esto, creemos que la presencia y la importancia del fragmento en Frankenstein no se reduce a un mero recurso estético a lo monstruoso y lo terrorífico. Mary Shelley, al igual que muchos de sus contemporáneos, entroncando con este entendimiento de una realidad profundamente cambiante que le ha tocado experimentar, estaba respondiendo en clave de ficción a todo lo que acechaba a la sociedad «moderna», al tiempo que canalizaba, a través de dicho recurso a lo fragmentario, y de forma profundamente psicológica, sus propias experiencias personales, como veremos a continuación.

2. LA MADRE DEL MONSTRUO: LAS CLAVES BIOGRÁFICAS DE UNA MUJER-AUTORA ESCINDIDA

Cuando nos acercamos a una determinada obra artística, se hace importante —en algunos casos, imprescindible - rastrear los principales hechos que marcaron el devenir de su creador o creadora antes o durante el proceso de construcción de dicha obra. Con esto no buscamos reconocer un producto cultural como mera emanación de una genialidad intrínseca al sujeto creador ya que, haciendo eco de una de las máximas nietzcheanas: «cuando la obra comienza a hablar, el autor debe callar» (Nietzsche, 2005: 70), sino comprender hasta qué punto la vida y el contexto de dicho sujeto han dejado huella directa o indirecta en su obra, enriqueciendo las lecturas que podemos hacer de la misma. Teniendo esto en mente, y remarcando el tratamiento plural que hemos querido dar en este trabajo a lo fragmentario, Mary Shelley y Frankenstein son un perfecto ejemplo de cómo la elección y el tratamiento de los temas centrales de una historia, la construcción de unos personajes y el devenir de una obra pueden entenderse en clave autobiográfica.

Algunos estudiosos ${ }^{6}$ de la obra de Mary Shelley consideran necesario realizar un análisis psicocrítico de sus obras, hasta el punto de que sus prolíficos escritos a modo de diario, a los que unimos sus cartas, actúan como paratexto para la comprensión y descodificación de sus cuentos, relatos y novelas. De acuerdo con la crítica feminista, por ejemplo, Frankenstein presenta, por un lado, una fuerte crítica a la inhabilidad para la 
paternidad y sus consecuencias (inhabilidad que, como veremos, Mary Shelley pudo conocer muy de cerca) y, por el otro, la realidad de la asignación de espacios sociales para hombres y mujeres, es decir, el ámbito público es exclusivo de los hombres, mientras que las mujeres quedan relegadas al ámbito doméstico; cuando incumplen dicha regla, acaban muertas. Los hombres, por otro lado, pese a sus amplios derechos de ir y venir, terminan por cometer errores irreparables que conducen a la muerte y la destrucción, véase la fatídica ocurrencia de Víctor Frankenstein. Lo mismo podría aplicarse a la trama de otra importante, pero mucho menos conocida, novela de Mary Shelley, The Last Man cuyos personajes masculinos principales, Adrian y Lord Raymond, están inspirados, por lo que todo indica, en Percy Shelley y Lord Byron, respectivamente (Shelley, 1993: 8).

En este epígrafe nos adentraremos, pues, en la vida y el contexto de Mary Shelley, tratando de rastrear los diversos acontecimientos que marcaron su historia, analizando los fragmentos de su trayectoria para tratar de comprender cómo es posible que ella «...entonces una jovencita, pudiera concebir y desarrollar una idea tan horrorosa?» (Shelley, 2014: 17). En nuestro caso de estudio, acercarnos a escuchar más de cerca la voz de la autora se hace, pues, ineludible.

Mary Wollstonecraft Shelley (de soltera Godwin) nació en Londres el 30 de agosto de 1797. Hija de una pareja de distinguidos escritores, los cuales se casaron para garantizar la respetabilidad de sus hijas en la sociedad británica conservadora, pero que estaban en contra del matrimonio como institución (Mellor, 1988: 2), en la que de un lado estaba su padre, William Godwin, filósofo y crítico político y del otro su madre, Mary Wollstonecraft, filósofa feminista que abogaba de forma fervorosa por la educación de las mujeres en la conservadora sociedad inglesa ${ }^{7}$. El más temprano infortunio que, indudablemente, marcó la vida de Mary Godwin fue no haber conocido a su madre, ya que ésta murió de fiebre puerperal —un mal muy común en la época debido, entre otras causas, a las malas condiciones de higienización de los médicos a la hora de realizar intervenciones en las parturientas - diez días después de dar a luz (Mellor, 1988: 1). Marcada por la separación temprana de su madre, Mary trató de leer las obras de ésta más de una vez, tal y como atestigua su diario; asimismo, buscaba paliar su ausencia visitando constantemente el St. Pancras Churchyard, lugar en el que yace Mary Wollstonecraft; allí, leía en voz alta los

${ }^{7}$ Con su obra $A$ vindication of the rights of woman: with structures on political and moral subjects, Mary Wollstonecraft estableció las bases del feminismo moderno. En ésta, pone de manifiesto que lo único que separa la mujer del hombre es la educación desigual que ésta recibe frente al segundo, hecho que debería ser paliado a través de una reformulación de dicha educación dispar. 
fragmentos de las obras publicadas de su madre, así como sus propias creaciones (Gilbert y Gubar, 1979: 223), como si buscara la muda aprobación y el beneplácito de una tempranamente arrebatada Mary Wollstonecraft para seguir con una afición que desde la infancia le había marcado (Shelley, 2014: 17).

Tras la muerte de Mary Wollstonecraft, la relación de William Godwin con sus hijas, especialmente Mary, estuvo lejos de ser idónea, como Don Locke pone de manifiesto en una de las más importantes biografías de William Godwin:

Godwin had found easy to express his obvious affection when his daughters were small, but as they all grew older he became remote and awkward, more dutiful tan sensitive, unable to show what he really felt for them. They, too, had to be fitted into his methodical timetable, with periods allotted when they might interrupt his writing or listen to his lately story. He would take them with him sometimes, to a lecture or the theatre or some other public occasion, but they were all very much in awe of him, a famous figure so they were told. (Locke, 1980: 217)

$\mathrm{Al}$ principio, todo parece indicar que padre e hija mantuvieron una buena relación, pero todo cambió cuando Godwin volvió a casarse. La búsqueda por la aprobación de su padre, unida a la devoción que mostraba hacia él, su único progenitor vivo, frente al rechazo que éste muchas veces demostraba ante cualquier intento de acercamiento por su parte, a la vez que mimaba y mostraba especial predilección por Fanny (media hermana de Mary, fruto de una relación de Mary Wollstonecraft anterior a Godwin), marcó profundamente a Mary, acentuando aún más su sentimiento de culpa hacia la muerte de su madre.

Poco tiempo después del fallecimiento de Mary Wollstonecraft, Godwin empezó su búsqueda por una nueva esposa, que pudiera ejercer también el papel de madre para sus hijas. La ansiedad que las niñas sentían, especialmente Mary, ante la idea de separarse de su padre cuando éste se iba de viaje, fuera por trabajo u ocio, queda clara en una carta que Godwin envió desde Irlanda el 11 de julio de 1800, a James Marshall, quien estaba encargado de cuidar a las niñas en su ausencia:

Their talking about me, as you say they do, makes me wish to be with them, and will probably have some effect in inducing me to shorten my visit. It is the first time I have been seriously separated from them since they lost their mother [...] Tell Mary I will not give her away, and she shall be nobody's girl but papa's. Papa is gone away, but papa will be very soon come back again. (Mellor, 1988: 6) 
El 21 de diciembre de 1801, Godwin se casó nuevamente, con la viuda Mary Jane Clairmont. Como recoge Anne K. Mellor, al parecer la madrasta no congeniaba especialmente con la joven Mary, más allá de estar pendiente de sus necesidades más básicas:

What sort of mother was Mrs. Godwin to her newly acquired stepdaughters? Mary Godwin clearly found her very difficult. Mrs. Godwin resented Mary's intense affection for Godwin. As Mary much later confessed to Maria Reveley Gisborne, her sensibility by the age of twelve was «covert-except that Mrs. Godwin had discovered long before my excessive \& romantic attachment to my Father». Visitors to the Godwin household intensified Mrs. Godwin jealousy by showing a special interest in Mary, the daughter of both of the most celebrated radical political thinkers of the day. (Mellor, 1988: 8)

Cabe decir que, al contrario de las hijas de Mrs. Godwin, a Mary no se le permitió acudir a la escuela, sino que recibió educación en casa, aprendiendo a leer y a escribir con Louisa Jones, ama de llaves y enfermera de Godwin. Sin embargo, pese a no haber sido educada fuera del hogar, Mary mostraba una inteligencia y un talento que superaban a los de su media hermana y de sus hermanastras.

La situación en la casa de los Godwin parecía tensarse cada vez más con los años. A la edad de trece años, Mary Godwin empezó a desarrollar una persistente enfermedad en la piel que le rendía dolorosas y extensas pústulas, especialmente en el brazo izquierdo, y que por lo que todo indicaba parecía tener un fondo emocional (Sunstein, 1989: 55). Frente a una dolencia que se mostraba reincidente y una situación familiar crítica, Godwin decide escribir a un conocido, William Baxter que vivía en Dundee, Escocia, para enviar a Mary a su casa durante unos meses. Pese a las circunstancias, Mary parece haber encontrado inspiración en las idílicas campiñas escocesas ${ }^{8}$, logrando también alcanzar allí la curación de su enfermedad epidérmica.

Cuando volvió a Londres tras su estancia en casa de los Baxter, Mary conoció al más nuevo frecuentador de su casa, un joven y fervoroso discípulo de su padre: Percy Bysshe Shelley. Cuando se conocieron, Percy Shelley tenía veinte años, Mary Godwin tenía quince. Respecto al ambiente de la casa de los Godwin, —y un hecho interesante a tener en cuenta a la hora de indagar en el panorama artístico-cultural en el que estaba inserta Mary- allí se

${ }^{8}$ Ella recuerda la temporada que vivió en Escocia en la Introducción a la edición de 1831 de Frankenstein: «Cuando era niña, viví sobre todo en el campo, y pasé un tiempo considerable en Escocia. Ocasionalmente hice alguna visita a otros lugares pintorescos, pero mi residencia habitual estuvo en las desoladas y lúgubres riberas norteñas del Tay, cerca de Dundee. Digo desoladas y lúgubres desde un punto de vista retrospectivo; no lo era para mi en aquel entonces. Eran los refugios de la libertad y el encantador territorio donde, sin que nadie se percatara de ello, podía vivir con las criaturas de mi imaginación.» (Shelley, 2014: 18) 
celebraban reuniones que contaban con la presencia de importantes intelectuales del momento ${ }^{9}$. Cabe destacar, entre esas figuras, a Samuel Coleridge (1772-1834), poeta romántico. Mary le oyó recitar uno de sus principales poemas The rime of the ancient mariner (Balada del viejo marinero) y los versos de éste están presentes en Frankenstein ${ }^{10}$. Es curioso pensar en esa inclinación que Mary mostraba hacia Coleridge, especialmente si tenemos en cuenta que él fue el poeta inglés del «fragmento» por excelencia, ya que reclamó las cualidades estéticas de la creación fragmentaria en poesía.

Es interesante mencionar aquí a uno de los principales poemas de Coleridge, escrito en 1816, dos años antes de la publicación de Frankenstein: Kubla Khan; or, A Vision in a Dream: A Fragment. En este poema, Coleridge expone en trescientos versos algo que había soñado, estando bajo el efecto de opiáceos; en su título aparece la palabra «fragmento», porque el poema queda interrumpido, debido a que, según cuenta el propio Coleridge, alguien llamó a su puerta mientras escribía, distrayéndole de su labor. Esta idea del poema como «fragmento», dentro de una dicotomía parte/todo, aparecía constantemente en las obras de Coleridge ${ }^{11}$; su estilo estaba marcado por el reclamo estético de lo fragmentario que formaba parte, asimismo — y a la vez añadía fuerza creativa - a la relación texto/paratexto. En el caso de Kubla Khan esto se ve claramente, ya que la concepción del poema en tanto que «fragmento» está relacionada con la plasmación de un supuesto sueño, que a su vez ha sido interrumpida por una presencia no esperada. Creemos que ha sido importante mencionar aquí a Coleridge porque Mary lo admiraba especialmente, sentía gran aprecio por sus obras, su estilo y sus ideas; asimismo, queda patente en la figura del poeta esta nueva forma de relacionarse con la creación artística, antes necesariamente cerrada, orgánica, únicamente

\footnotetext{
${ }^{9}$ «Mary would often listen quietly in a corner while Godwin carried on political, philosophical, scientific, or literary conversations with such visitors as William Wordsworth, Charles Lamb, Samuel Coleridge, Thomas Holcroft, John Johnson, Humphrey Davy, Horne Tooke, and William Hazlitt. » (Mellor, 1988: 11)

${ }^{10} \ll$ como aquel que, en un sendero solitario,

hace su camino con temor y miedo,

y habiéndose girado una vez, continúa andando

y no gira más la cabeza,

porque sabe que un terrible demonio

le sigue muy de cerca. » (Shelley, 2014: 82)

${ }_{11} \ll[\ldots]$ Even when the poem was soon judged very positively, the discussion remained within the confines of the question of partiality and meaning: «Kubla Khan» was so perfect because it was purely sensual music and imagery, and did not at all need to be more, or whole. In both cases the poem was considered as a fragment, while the possibility of one's understanding it laid claim to totalization. Either one could wholly understand it - but unfortunately there was no whole to understand - or one did wholly understand it, and that meant that one understood that it was not to be understood as a whole. » (Bathi, 1981: 1035)
} 
fragmentada por devenires históricos inevitables, ahora fragmentada como un reclamo estético, reflejo de una nueva fuerza creativa ${ }^{12}$.

Ahora bien, volvamos al encuentro de la joven Mary Godwin con Percy Bysshe Shelley. Cuando Shelley entra en la vida de los Godwin, lo hace a través de una carta en la cual ponía de manifiesto su profunda inclinación hacia los ideales político-filosóficos de cuño librepensador propugnados por William Godwin ${ }^{13}$. Por aquél entonces, Godwin no contaba con una situación financiera especialmente cómoda, por lo que la presencia del monetariamente abastado Shelley en las tertulias celebradas en su casa, iba más allá de las contribuciones intelectuales que por ventura éste podría hacer. Shelley por aquel entonces estaba casado con Harriet Westbrook, la hija de un posadero inglés con la cual se había fugado a la temprana edad de diecinueve años (ella tenía dieciséis). Pero su matrimonio no le impidió enamorarse de la joven Mary Godwin, hija de su admirado William Godwin con la ilustre Mary Wollstonecraft, una chica de notoria inteligencia y sensibilidad poética con quien empezó a crear lazos.

Como hemos apuntado anteriormente, Mary Godwin solía visitar la tumba de su madre en el St. Pancras Churchyard constantemente. Shelley no tardó en acompañarla en estas visitas, pero solían llevar con ellos a Jane Clairmont, media hermana de Mary, seguramente para no levantar sospechas indeseadas ante sus encuentros amorosos; ésta más tarde declararía: «They always sent me to walk some distance from them, alleging that they wished to talk on philosophical subjects and that I did not like or know anything about those subjects - I willing left. I did not hear what they talked about» (Mellor, 1988: 20). Lo cierto es que la atracción emotiva y sexual que nutrieron mutuamente se fue haciendo cada vez más visible al exterior, hecho que no agradó a William Godwin —entre otras cosas, debido a que Percy Shelley ya estaba casado- quien, no más enterarse de los encuentros amorosos que mantenían su hija y su pupilo, inquirió que éste se alejara de ella. Pese a los esfuerzos de su padre, y tras una amenaza de suicidio por parte de Shelley, Mary decide fugarse con él a Francia en la mañana del 18 de julio de 1814, convenciendo a una Jane Clairmont (que más

\footnotetext{
${ }^{12}$ Sobre el tema unidad/fragmentación en la creación decimonónica, especialmente en las obras de Samuel Coleridge y William Blake, es interesante revisar: Abrams, Meyer Howard (1992): «La unidad perdida y la integridad ganada: Blake y Coleridge», en El romanticismo: tradición y revolución, Madrid, Visor: 253-275.

${ }_{13}$ «You will be surprised at hearing from a stranger... The name of Godwin has been used to excite in me feelings of reverence and admiration, I have been accustomed to consider him a luminary too dazzling for the darkness which surrounds him, and from the earliest period of my knowledge of his principles I have ardently desired to share on the footing of intimacy that intellect which I have delighted to contemplate its emanations [...]» (Jones, 1964: 219)
} 
tarde sería conocida como Claire Clairmont) deseosa de escaparse del control de su rigurosa madre, de que les acompañara en su trayectoria.

No es necesario emplear demasiado esfuerzo para llegar a la conclusión de que William Godwin se mostró ampliamente disgustado con el comportamiento de Mary y Percy; resulta contradictorio pensar cómo un hombre que en más de una ocasión se había mostrado tan fervorosamente contrario al matrimonio como institución, a la vez que defendía el amor libre, pudiera comportarse de manera tal, pero lo cierto es que su enfado llegó hasta el punto de no dirigirle la palabra a su hija hasta años después, aunque siguiera manteniendo cierto contacto con Shelley, especialmente para continuar recibiendo la ayuda financiera que éste le proporcionaba. Lo cierto es que la actitud de Godwin hizo que Mary se aferrara aún más a Shelley, buscando en él el reflejo de un padre desde hacía demasiados años ausente, algo que queda patente en sus escritos:

Goodnight my love - tomorrow I will seal this blessing on your lips dear good creature press me to you and hug your own Mary to your heart perhaps she will one day have a father till then be everything to me love - \& indeed I will be a good girl and never vex you any more [...] (Bennet, 1983: 84)

Ahora bien, cuando regresaron a Londres, Mary y Percy evitaron el convivio social, puesto que, de cara a la conservadora sociedad decimonónica inglesa, su relación no resultaba bajo ningún parámetro aceptable. Para complicar aún más la situación, Mary se queda embarazada, dando a luz a su primera hija Clara en 22 de febrero de 1815, una niña que nació prematura y que tenía pocas probabilidades de supervivencia. Sin embargo, y contra todo pronóstico, la pequeña Clara sobrevivió a las dos primeras semanas de vida, atendida por una cuidadosa Mary Godwin. Estas dos semanas fueron suficientes para que Mary creara fuertes lazos emocionales con su hija, por lo que encontrarla muerta en la mañana del 6 de marzo resultó un duro golpe psicológico que queda atestiguado en las páginas de su diario inmediatamente posteriores a la muerte del bebé:

March 9:

Still think about my little baby - 'tis hard, indeed, for a mother to lose a child. March 16:

Stay at home; net, and think about my little dead baby. This is foolish, I suppose; yet, whenever I am left alone to my own thoughts, and do not read to divert them, they always come back to the same point - that I was a mother, and I am so no longer.

March 23: 
Dream that my little baby came to life again; that it had only been cold, and that we rubbed it before the fire, and it lived. Awake and find no baby. I think about the little thing all day. Not in good spirits. (Jones, 1947: 40-41)

Este sueño, descrito en la página del diario dedicada al día 23 de marzo, asombró constantemente a la joven Mary. Soñaba que Clara había renacido, que únicamente había estado congelada y que, tras acercarla al fuego, la niña había recobrado vida; al despertarse, y darse cuenta de que todo había sido una trampa de su inconsciente, Mary se sumía aún más en la depresión. Durante los meses que se siguieron, y aún afectada por la muerte de Clara, la dependencia emocional de Mary hacia Percy se hizo aún más intensa, mientras que éste parecía disfrutar especialmente de la compañía de Claire Clairmont, quién seguía viviendo con ellos. Una vez transcurrieron seis meses, Mary se quedó embaraza nuevamente, esta vez de un niño al que llamó William, como su padre, aunque por aquel entonces padre e hija siguieran sin intercambiar palabra.

Es a mediados de 1816 cuando tiene lugar un episodio en la vida de Mary Godwin que nos interesa especialmente: su viaje a Ginebra, a la casa de Lord Byron. Claire Clairmont, nutrida por una gran admiración hacia un talentoso y misterioso Lord Byron, comenzó a comunicarse con él por carta, pidiéndole consejos para escribir y enviándole algunas de sus creaciones, las cuales, al parecer, no plasmaban el mismo talento que las de su hermanastra. En mayo de 1816, Claire convence a Mary y a Percy para que vayan hasta Ginebra para encontrarse con Byron y, así, la familia, junto con el pequeño William de cuatro meses de edad, llegan a la Villa Diodati y, allí, comienza la amistad de Percy y Mary con Lord Byron, además del romance de éste con Claire.

En 15 de junio de 1816, Mary, Percy, Claire, Byron y John Polidori, médico personal de Byron, se reunieron a las orillas del Lago Lemán. Allí se encuentra el germen de Frankenstein, ya que en este lugar Byron decide retar a sus invitados para que escriban historias de terror. En la introducción de la edición de 1831 de Frankenstein, Mary deja constancia de cómo se le ocurrió semejante idea:

Mi imaginación, sin que nadie la llamara, se adueñó de mí y me mostró el camino, dotando las sucesivas imágenes que se despertaban en mi mente con una nitidez que iba mucho más allá de los habituales límites de una ensoñación. Vi —con los ojos cerrados, pero como una imagen mental muy clara-, vi al pálido estudiante de artes diabólicas arrodillado junto a la cosa que había logrado reunir. Vi la espantosa monstruosidad de un hombre allí tendida, y luego, mediante el funcionamiento de alguna máquina poderosa, observé que mostraba signos de vida, y se despertaba con los movimientos torpes de un ser medio vivo. Debía 
de ser horroroso, porque absolutamente horrorosos deberían ser todos los intentos humanos de imitar la fabulosa maquinaria del Creador del mundo [...] Se duerme, pero se despierta; abre los ojos, y ve aquella cosa horrorosa de pie, a su lado, abriendo las cortinas del dosel, y mirándolo con aquellos ojos inquisitivos amarillentos, y acuosos. Abrí los míos aterrorizada. La idea se apoderó de mí de tal modo que me recorrió un escalofrío de miedo y deseé cambiar las fantasmales visiones de mi imaginación por las realidades que me rodeaban. (Shelley, 2014: 22-23)

A partir de ahí, Frankenstein empezó a ganar forma y en el año nuevo de 1817, Mary Shelley, ya casada con Percy Shelley desde el 30 de diciembre de 1816, escribe en su diario, haciendo referencia al acercamiento de la publicación de la novela: «Fran ${ }^{\text {tein }}$ comes. » (Jones, 1947: 55)

Ahora bien, una vez nos hemos acercado a los principales hitos biográficos de Mary Shelley hasta la publicación de Frankenstein, creemos que es necesario poner de manifiesto por qué consideramos que los mismos son de conocimiento ineludible a la hora de «juntar» las partes para interpretar algo tan capital en la novela como la naturaleza fragmentaria de la criatura, especialmente de su psique escindida. Hemos podido concluir, así como muchos estudiosos de la obra de Mary Shelley, como hemos mencionado en la introducción de este epígrafe, que sus escritos más personales, a modo de diario, pueden funcionar como paratexto para la comprensión de los principales temas de sus novelas. Y es que Mary Shelley, al ser una escritora tan prolífica en dichos diarios, nos ha dejado numerosas claves para conocer una gran parte de sus aflicciones, sus deseos, sus fantasmas y sus inquietudes.

Para comenzar, habría que tratar de ensamblar estos fragmentos biográficos que ponen de manifiesto los retazos psicológicos de una mujer, en muchos aspectos, escindida. Como hemos apuntado, el sentimiento de culpabilidad y abandono estuvieron presentes en la vida de Mary Shelley desde su más tierna infancia. El haber crecido sin una madre, al tiempo que era emocionalmente ignorada por su padre, dejó enorme huella en su personalidad; y es que queda claro que Mary se cuestionaba constantemente acerca de su propia identidad y de su lugar en el mundo. Asimismo, se hace patente el trauma que le supuso perder a tres de sus hijos una vez nacidos (Clara, que murió en 1815, Clara Evangelina, que había nacido en 1817 y murió por una intensa fiebre en 1818 y William, que murió a la edad de tres años de malaria en 1819) (Mellor, 1988: 15-20) y abortar espontáneamente a otros dos, antes de dar a luz a Percy Florence, el único de sus hijos que logró sobrevivir (llegando a edad de setenta años, longeva, si se tienen en cuenta los parámetros de aquel momento). 
La obsesión de Mary con el parto y sus complicaciones puede retrotraerse hasta su mismo nacimiento, ya que, recordemos, su madre murió poco después de dar a luz; asimismo, su frustración por tener a sus hijos arrebatados queda reflejada en el personaje Idris de su novela The Last Man (1826), mujer cuya personalidad está marcada por un fervoroso, pero infructífero y casi obsesivo, deseo de ser madre. Podríamos decir, por el estudio de su biografía, que Mary era, en sí misma, una mujer psicológicamente fragmentada, en ocasiones atormentada, una Eva del Paraíso Perdido (Gilbert y Gubar, 1979: 213-247) miltoniano que buscaba exorcizar sus fantasmas y exculparse en clave de ficción.

Asimismo, cabe mencionar que las figuras paternas que Mary Shelley pudo conocer a lo largo de su vida, más allá de la de su padre — que hemos intentado exponer ampliamente aquí- estuvieron lejos de ser idóneas. De un lado estaba Percy Shelley que, muchas veces ensimismado, no le brindaba el apoyo necesario en el cuidado de los niños cuando éstos aún vivían, ni tampoco a la hora de afrontar la muerte de los mismos; del otro, estaba su amigo Lord Byron quien, presa de sus muchos excesos, había dejado embarazada a Claire Clairmont, pero que había descuidado a la pequeña Alba Allegra desde antes de su nacimiento (la niña murió de tifus o malaria, no se sabe con seguridad, a la edad de cinco años). Queda claro que Mary Shelley no tenía en las figuras masculinas que le habían rodeado a buenos ejemplos de un responsable ejercicio de la paternidad.

Acercándonos a Frankenstein, podemos ver en la construcción de los personajes principales de la novela, un claro reflejo de las consecuencias del abandono paterno: nuestro ambicioso, pero descuidado e irresponsable Dr. Víctor Frankenstein una vez termina su tarea, no tiene otro impulso que el de huir, abandonando a la criatura que ha traído a la vida a su propia suerte. Este abandono tiene, a su vez, en el «monstruo» una consecuencia: «Creador insensible y despiadado...! Me otorgasteis sensaciones y pasiones, y luego me arrojasteis al mundo para desprecio y horror de la humanidad» (Shelley, 2014: 181) y

Pero...¿dónde estaban mis amigos y mis parientes? Ningún padre había visto mis días de infancia, ninguna madre me había bendecido con sonrisas y caricias; y si existieron, toda mi vida pasada no era ya más que una mancha, un vacío oscuro en el cual me resultaba imposible distinguir nada. Desde mi primer recuerdo yo había sido como era en esos momentos, tanto en altura como en proporciones. No había visto a nadie que se me pareciera, ni que quisiera mantener ninguna relación conmigo. ¿Qué era yo? La pregunta surgía una y otra vez, y sólo podía contestarla con lamentos (Shelley, 2014: 163)

En el fragmento anteriormente expuesto, la criatura habla, además del abandono 
del padre, de la inexistencia de una madre. Como hemos expuesto, Mary Shelley conocía de primera mano ambas sensaciones. Asimismo, el «monstruo» de Frankenstein narra todo lo vivido tras su huida del laboratorio de Víctor, centrándose especialmente en los momentos que pasó en la cueva, observando desde lejos a la familia De Lacey. Cuando decide acercarse a ellos, lo que recibe a cambio es rechazo y horror ante su apariencia. El monstruo mantiene, pues, que nació bueno, pero fue la actitud de los demás individuos hacia él, para empezar la falta de empatía de su propio padre/creador, lo que le hizo malo. Este argumento hace eco de la más conocida máxima del pensador francés Jean-Jacques Rousseau, es decir, el mito del «buen salvaje», el que expone en una de sus obras capitales, el Emilio, la cual Mary Shelley leyó en 1816, coincidiendo con el proceso de escritura de Frankenstein. (Mellor, 1988: 47-51)

Queda claro que la construcción de los dos personajes principales, es decir, el Dr. Frankenstein y su criatura, se concibe de tal modo que en el devenir de la narración el lector se pregunta quién es el verdadero monstruo en la historia. Es curioso tener en cuenta que la criatura sin nombre ha sido bautizada a posteriori en el proceso de recepción de la obra, como ya hemos mencionado, mimetizándose con su creador a través de sus nombres coincidentes. Creemos que es interesante apuntar la intencionalidad moral que tiene Mary en la novela, puesto que pone de manifiesto los peligros de un cientifismo «mal direccionado» (según ella), por un lado, y por el otro, muestra las consecuencias de la existencia de una criatura que no ha conocido a una madre y cuyo padre-creador ha rehuido de su responsabilidad, mostrando una clara inhabilidad para la paternidad. La psique de esta criatura, «buena por naturaleza», no podría convertirse en otra cosa que un reflejo fidedigno de su apariencia fragmentada.

En la novela se hace evidente, asimismo, la preocupación que tenía Mary Shelley hacia la praxis de la «mala ciencia» y las consecuencias que ésta podría tener en la sociedad; dicha preocupación se personifica en Victor Frankenstein. Los resultados de la contravención cometida por el Dr. Frankenstein se muestran desastrosos y él acaba sintiendo directamente el peso de su decisión, a través de la desgracia acaecida en su familia y en su propia vida. Otro error cometido por el científico ha sido el de reducir a su creatura a un mero conjunto de fragmentos muertos, a un mero experimento que gracias a la electricidad ha cobrado vida. El Dr. Frankenstein no se ha preocupado en instruir a su «monstruo», un ser bueno por naturaleza que se ha corrompido gracias a la negligencia de su «padre». El contenido moralizante se hace claro, pues, en la figura de Victor como un moderno Prometeo, castigado por su prepotencia como científico y su negligencia como padre y, al igual que su análogo de la mitología griega, punido duramente por su bybris. Como la propia 
autora pone de manifiesto en la introducción de la novela: «[...] porque absolutamente horrorosos deberían ser todos los intentos humanos de imitar la fabulosa maquinaria del Creador del mundo» (Shelley, 2014: 17). El contexto científico de la novela, así como la interiorización, plasmación y crítica del mismo por parte de la autora se hace necesario a la hora de aportar un fragmento contextual más para comprenderla en su totalidad.

Creemos que quedan claras las analogías entre Frankenstein y los principales hitos biográficos de su creadora. Como mencionábamos al inicio del epígrafe anterior, consideramos que en este caso el recurso a la vida de la autora se hace imprescindible y únicamente añade riqueza interpretativa y contextual para la comprensión del texto. Todo ello nos lleva a concluir que el marcado trasfondo moral, espiritual y de crítica social caracterizan fuertemente a Frankenstein. Todo ello, sin perder de vista el momento al que le tocó a Mary Shelley vivir —es decir, la sociedad británica decimonónica, eminentemente conservadora - al que supo, como algunas de sus contemporáneas — mientras que otras tantas de ellas, como es sabido, fueron enmudecidas y relegadas al ostracismo- criticar y, en la medida de lo posible, sobrevenirse al mismo.

\section{CONCLUSIONES}

¿Por qué hemos hablado de fragmentos? Una vez nos hemos acercado al panorama estético-cultural en el que la obra se inscribe, momento en el que, como hemos podido observar, el fragmento se convierte en una categoría estético-epistemológica que marcó profundamente el terreno teórico y la creación artística, ha sido posible observar que Frankenstein, en todas sus particularidades, entronca con esta visión decimonónica acerca de lo fragmentario, especialmente en sus consecuencias, pero también posibilidades expresivas. A través de la construcción de sus dos personajes principales —además del esbozo de los secundarios, puesto que la poca fuerza de los personajes femeninos, por ejemplo, encarna asimismo una importante crítica social- Mary Shelley formaría parte de este conjunto de intelectuales y artistas que reaccionaron frente a los convulsos acontecimientos sociopolíticos que marcaron su contexto (y que crearon a sus propios «monstruos»). La autora supo canalizar dicha reacción mediante la expresión artística. Frankenstein, la criatura y el doctor que la protagonizan, así como los cuadros de Friedrich, los fragmentos de Schlegel, los textos de Schiller y los cuadros de Géricault, están ligados por semejantes inquietudes 
estético-epistemológicas que las convierten en fragmentos intrínsecos de un amplio sistema cultural.

Por otro lado, cuando nos disponemos a analizar los principales hechos que marcaron la vida de Mary Shelley, no resulta extraño comprender por qué la visión fragmentaria tiene cabida en su obra, de modo que descifrar las claves autobiográficas de la novela se hace ineludible a la hora de comprender toda su complejidad. Más allá de formar parte de un contexto en el que el fragmento se erige como categoría estético-epistemológica, Mary Shelley experimentó circunstancias vitales que han provocado en ella escisiones psicológicas, marcando sin lugar a dudas su visión del mundo, dejando profunda huella en Frankenstein. Desde una infancia marcada por carencias afectivas importantes, pasando por los retazos de una adultez conturbada, hasta culminar en los retos de convertirse en una mujer escritora en la conservadora sociedad inglesa decimonónica, Mary Shelley presentó escisiones que son apreciables desde una lectura psicológica de la obra, respaldada por un estudio de sus diarios y cartas. A través de dicha lectura podemos extraer interesantes conclusiones acerca, principalmente, de la psique fragmentada de la criatura que emergió de su imaginación, resultado del abandono y de la profunda inadaptación social, que conllevaron a la infructífera búsqueda por una identidad.

En Frankenstein, Mary Shelley logra canalizar todas estas inquietudes en clave de ficción, a través de una historia de gran carga filosófica y moral que dio lugar a metáforas psicosociales tanto en el entorno inmediatamente cercano a su publicación, como en contextos muy posteriores a la misma. 


\section{BIBLIOGRAFÍA}

Abrams, Meyer Howard (1992): «La unidad perdida y la integridad ganada: Blake y Coleridge», en El romanticismo: tradición y revolución, Madrid, Visor: 253-275.

Baldick, Chris (1990): «The monster speaks», en Frankenstein's shadow: Myth, monstrosity, and nineteenth-century writing, New York, Oxford University Press: 33-35.

Bathi, Timothy (dec. 1981): «Coleridge's Kubla Khan and the fragment of Romanticism», MLN Comparative Literature, Vol. 96, N5: 1035-1050.

Benjamin, Walter (2017): «Sistema y concepto», en El concepto de crítica de arte en el romanticismo alemán, Madrid, Abada Editores: 48-65.

Bennet, Betty (ed.) (1983): The letters of Mary Wollstonecraft Shelley, Baltimore, The John Hopkins University Press.

Gilbert, Sandra, Gubar, Susan (1979): «Horror's Twin: Mary Shelley’s Monstrous Eve», en The Madwoman in the Attic. The Woman Writer and the Nineteenth-Century Literary Imagination, New Haven and London, New Haven and London Yale University Press: 213-247.

Jones, Frederick (ed.) (1947): Mary Shelley's journal, Norman, University of Oklahoma Press.

Jones, Frederick (ed.) (1964): The letters of Percy Bysshe Shelley, Oxford, The Clarendon Press.

Locke, Don (1980): A fantasy of reason. The life and thought of William Godwin, London, Routledge.

Marchán Fiz, Simón (2008): «La disolución de lo clásico en el relativismo del gusto», en Anales de Historia del Arte (volumen extraordinario): 427-446.

Marchán Fiz, Simón (2010): «La disolución en el relativismo del gusto», en La disolución del clasicismo y la construcción de lo moderno, Salamanca, Ediciones Universidad de Salamanca: 109-171.

Marrades, Julián (1997): «A partir de Schiller: naturaleza, juego y libertad», en J. E. Corbí y C. J. Moya (eds.). Ensayos sobre Libertad y Necesidad, Valencia, Pre-textos: 91-110.

Mellor, Anne. K. (1988): Mary Shelley. Her life, her fiction, her monsters, New York and London, Routledge.

Neibaur, James (2017): «Frankenstein», en The monster movies of Universal Studios, Maryland, Rowman \& Littlefield: 11-20.

Nietzsche, Friedrich (2005): Ideas Fuertes, Buenos Aires, Longseller: 70. 
Nochlin, Linda (1995): The body in pieces: the fragment as a metaphor of modernity, New York, Thames and Hudson.

Schiller, Friedrich (1990): Kallias. Cartas sobre la educación estética del hombre, Barcelona, Anthropos.

Schlegel, Friedrich (2009): Fragmentos sobre la incomprensibilidad, Barcelona, Marbot Editores.

Shelley, Mary (1993): The Last Man (Edición de 1826), Nebraska, University of Nebraska Press.

Shelley, Mary (2014): Frankenstein o el Moderno Prometeo (Edición de 1831), Barcelona, Espasa Libros.

Sunstein, Emily (1989): «The aspiring child», en Mary Shelley: Romance and reality, Baltimore, The John Hopkins University Press: 9-62. 
SOBRE LA AUTORA

\section{Amanda Bittencourt Sarmiento}

Amanda Bittencourt Sarmiento es graduada en Historia del Arte por la Universidad Autónoma de Madrid (2015). Tiene un máster en Estudios Artísticos, Literarios y de la Cultura (2017) por la misma universidad, y en Grafística y Autenticación de Obras de Arte por la Escuela Internacional de Criminología y Criminalística (2019). Actualmente se encuentra desarrollando su tesis doctoral, la cual versa sobre el ser artificial y la ciencia ficción, dentro del programa de doctorado en Estudios Artísticos, Literarios y de la Cultura de la Universidad Autónoma de Madrid.

Contact information: Universidad Autónoma de Madrid, amandabittsarm@gmail.com 